\title{
SEGURANÇA HÍDRICA EM MATO GROSSO: PANORAMA E DESAFIOS
}

Dempsey Thrweyce Alves da Silva - dempsey_alves@ hotmail.com Universidade Federal de Mato Grosso

Rafaela de Araújo Costa - rafaela_araujocosta@ hotmail.com Universidade Federal de Mato Grosso

Emanuelly Veronica Soares Leoncio - manuleoncio01@ @otmail.com Universidade Federal de Mato Grosso

Ricardo de Sousa Carneiro - ricardo.carneiro.mt@gmail.com Universidade Federal de Mato Grosso 


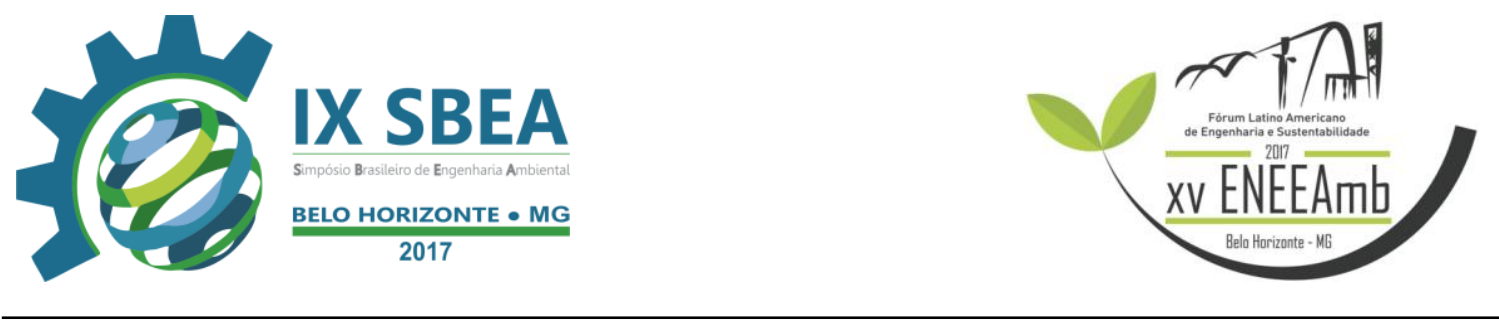

\section{RESUMO}

O termo "segurança hídrica" é cada vez mais constante no meio cientifico e tem ganhado espaço na sociedade. Isso pode estar relacionado aos eventos de escassez hídrica que tem causado impactos significativos em diversos países, aumentando a preocupação em torno dessa temática. Diante desse cenário, esse trabalho tem por objetivo geral discutir o panorama da segurança hídrica no estado de Mato Grosso. Para a realização do deste estudo utilizou-se basicamente de dois métodos: a pesquisa de informações junto à órgãos competentes da área de recursos hídricos e senso do IBGE e a revisão de literatura enfocada em bibliografias que apresentam analises e discussões a respeito da situação atual e perspectivas futuras para a segurança hídrica. Os projetos em desenvolvimento têm conseguido avanços, com destaque para a atenção social que está sendo gerada com a divulgação destes e os desafios encontrados podem ser resolvidos desde que haja uma mudança na visão dos atores que compõe a gestão de recursos hídricos e aplicação de instrumentos já previstos nas legislações em nível federal e local.

Palavras-chave: Segurança hídrica, Recursos hídricos e Mato Grosso.

\section{INTRODUÇÃO/OBJETIVO}

O Brasil possui grandes reservas de recursos hídricos, representado $12 \%$ da água doce do mundo, porém temos vivenciado eventos críticos de escassez em diversas regiões do país. O caso mais marcante, no estado de São Paulo, que deixou milhares de pessoas sem água, deu mais ênfase à questão de como assegurar que a população não sofra com a escassez.

O termo "segurança hídrica" é cada vez mais constante no meio cientifico e tem ganhado espaço na sociedade. Isso pode estar relacionado aos eventos de escassez hídrica que tem causado impactos significativos em diversos países, aumentando a preocupação em torno dessa temática. Para SANTOS (2016) o uso do termo segurança hídrica tem aumentado nas últimas décadas devido o reconhecimento da água como um direito humano, e a introdução de uma acepção mais integrativa do conceito de segurança hídrica, que se deu a partir dos anos 2000, com a realização do Segundo Fórum Mundial do Global Water Partnership (GWP).

No Brasil, a criação da lei das águas em 1997 foi um importante avanço para tornar as ações de proteção desse recurso mais concreta. Porém, ainda existem diversos problemas quanto à manutenção da qualidade dos mananciais, emergindo a necessidade de melhorias na gestão desse bem de uso comum e sensibilização dos usuários para reconhecer a importância da preservação. Além disso, a redução da disponibilidade hídrica interliga-se a outras áreas essenciais. A situação cada vez mais grave da segurança hídrica está começando a afetar os sistemas alimentar e energético mundiais, com maiores impactos sobre as regiões mais pobres e vulneráveis do planeta (IGBP, 2012).

Diante desse cenário, esse trabalho tem por objetivo geral discutir o panorama da segurança hídrica no estado de Mato grosso. E objetivos específicos: apresentar a fundamentação legal para segurança hídrica a nível federal e estadual; analisar o cenário 


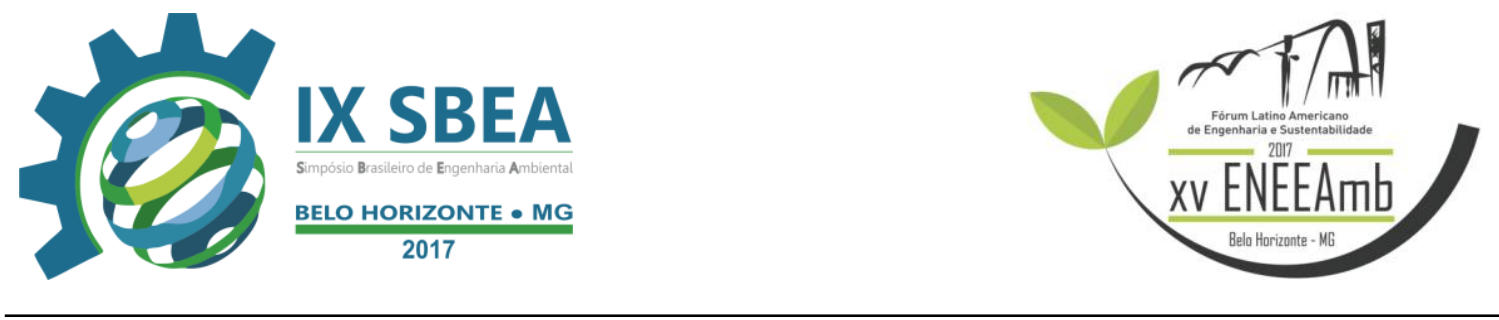

atual da disponibilidade hídrica com base em documentos de órgãos de recursos hídricos do estado de Mato grosso; apresentar os projetos que estão em desenvolvimento no estado nessa temática e traçar os desafios futuros para a segurança hídrica em Mato grosso.

\section{METODOLOGIA}

Para a realização do deste estudo utilizou-se basicamente de dois métodos: o levantamento de informações junto à órgãos competentes da área de recursos hídricos e senso do IBGE; e a revisão de literatura enfocada em bibliografias que apresentam analises e discussões a respeito da situação atual e perspectivas futuras para a segurança hídrica. As informações levantadas dizem respeito à situação da qualidade e quantidade de água, e as ações e projetos de esfera pública em andamento no estado com intuito de assegurar a disponibilidade de água para a população. $\mathrm{Na}$ revisão de literatura buscaram-se bibliografias que abordam os instrumentos e ações relevantes a segurança hídrica, experiências em outras regiões do país e analises dos mecanismos legais.

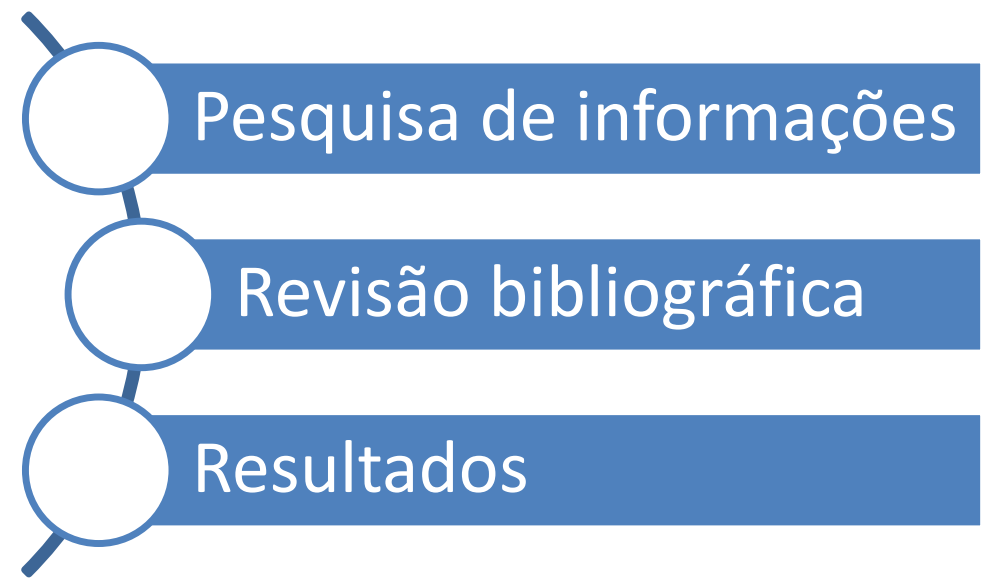

Figura 1- Fluxograma das etapas do estudo

Segundo o último levantamento do Instituto Brasileiro de Geografia e Estatística (IBGE) realizado em 2010, Mato Grosso possui 3.035.122 habitantes, o que representa $1,59 \%$ da população brasileira. Vivem na zona urbana $81,9 \%$ da população, contra $18,1 \%$ da zona rural. O número de homens corresponde a $51,05 \%$, sendo ligeiramente superior ao das mulheres, que representa $48,95 \%$.

\section{RESULTADOS E DISCUSSÃO}

\section{Fundamentação legal para segurança hídrica}

A política nacional de recursos hídricos é o marco mais importante para a gestão de aguas no Brasil na atualidade. Ela apresenta como objetivos (BRASIL, 1997):

I - Assegurar à atual e às futuras gerações a necessária disponibilidade de água, em padrões de qualidade adequados aos respectivos usos; 


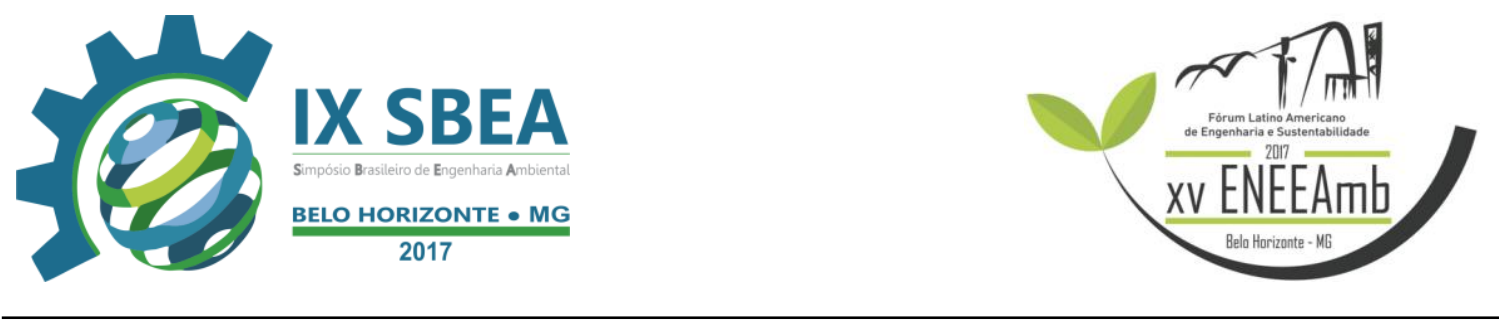

II - A utilização racional e integrada dos recursos hídricos, incluindo o transporte aquaviário, com vistas ao desenvolvimento sustentável;

III - a prevenção e a defesa contra eventos hidrológicos críticos de origem natural ou decorrentes do uso inadequado dos recursos naturais.

Tais objetivos vão ao encontro do conceito de segurança hídrica apresentado pela UN-WATER (2013), que a define como:

"A capacidade da população de garantir o acesso seguro e sustentável a quantidades adequadas de água de qualidade aceitável para sustentar os meios de subsistência, bem-estar humano e desenvolvimento socioeconômico, para assegurar a proteção contra a poluição transmitida pela água e os desastres a ela relacionados, e, para a preservação dos ecossistemas em um clima de paz e estabilidade política. '

Observou-se um debate mais expressivo sobre o tema com o início da elaboração do Plano de Segurança Hídrica Nacional (PNSH). O PNSH foi produzido no âmbito do Projeto Interáguas conjuntamente pela Agência Nacional de Águas (ANA), o Ministério da Integração e o Banco Mundial. Tem como objetivo a definição das principais intervenções estruturantes e estratégicas na gestão dos recursos hídricos visando garantir a oferta de água para o abastecimento humano e para o uso em atividades produtivas, e reduzir os riscos associados a eventos críticos (SANTOS, 2016).

Assim, o plano organiza-se em quatro pontos importantes (ANA; MINISTÉRIO DA INTEGRAÇÃO NACIONAL, 2012):

I - Estabelecimento de critérios de seleção de intervenções para compor o plano;

II - Seleção de propostas de intervenção - entre as já existentes que sejam chave para a solução de garantia de oferta de água ou de controle de inundações nas diversas regiões brasileiras;

III - Identificação de lacunas de soluções para as áreas em que eventos extremos de seca ou inundação ocorrem com maior frequência ou lacunas de soluções frente às necessidades de desenvolvimento regional, definindo o escopo para a realização de estudos complementares, estudos de viabilidade e projetos; IV - Elaboração de todos os elementos necessários para a realização das intervenções componentes do plano.

A Lei $\mathrm{n}^{\circ} 9.433$ de 8 de janeiro de 1997 apresenta no seu Art. $5^{\circ}$ os instrumentos da Política Nacional de Recursos Hídrico:

I - Os Planos de Recursos Hídricos;

II - O enquadramento dos corpos de água em classes, segundo

os usos preponderantes da água;

III - A outorga dos direitos de uso de recursos hídricos;

IV - A cobrança pelo uso de recursos hídricos;

V - A compensação a municípios;

VI - O Sistema de Informações sobre Recursos Hídricos 


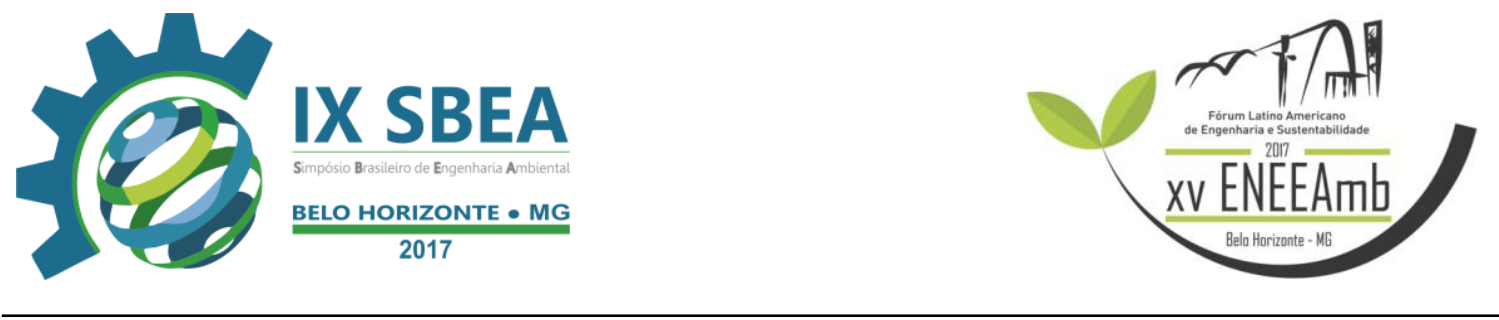

Dois instrumentos importantes são a outorga pelo uso dos recursos hídricos e a cobrança pelo uso da água. A outorga é a licença de uso concedida pelo Estado, sendo este o gerenciador dos recursos hídricos (BORGES \& ROSA, 2015). A outorga é o principal meio de administração da oferta de água, e para se ter um processo de outorga adequado é necessário um eficiente sistema de informações de apoio à decisão, tanto em relação aos dados e informações básicas, quanto às metodologias de tratamento dos mesmos (SILVEIRA et al, 1998).

Em relação a cobrança, a tarifação pelo uso dos recursos hídricos é o que possibilita o funcionamento de todo o sistema por meio do financiamento do programa de investimentos da bacia. Por meio da cobrança dos usuários, de acordo com a realidade de cada Bacia Hidrográfica, pode-se ter redução do consumo de água e maior preocupação com a poluição e preservação (BORGES \& ROSA, 2015).

No âmbito estadual, a Lei Estadual n 6.945 de 05 de novembro de 1997 dispõe sobre a Política Estadual de Recursos Hídricos no Estado de Mato Grosso. Ela apresenta os seguintes instrumentos:

I - O Plano Estadual de Recursos Hídricos;

II - O enquadramento dos corpos de água em classes, segundo os usos preponderantes da água;

III - A outorga dos direitos de uso de recursos hídricos;

IV - A cobrança pelo uso de recursos hídricos; V - o Sistema de Informações sobre Recursos Hídricos.

Em relação ao município de Cuiabá, a Lei Complementar nº 389 de 03 de novembro de 2015 estabelece no seu Art. 80 a Zona de Segurança Hídrica (ZSH), a qual compreende as áreas a montante e no entorno das instalações de captação de água bruta para tratamento e distribuição ao consumo humano, bem como a continuidade dos cursos hídricos.

\section{Cenário atual da disponibilidade hídrica em Mato grosso}

Mato Grosso abriga em seu território três das doze bacias hidrográficas existentes no país: Paraguai, Araguaia/Tocantins e Amazônica, sendo esta última a maior do mundo com 7 milhões de $\mathrm{km}^{2}$ de extensão (MATO GROSSO, 2017). Mas mesmo diante da grande reserva de água doce, Mato grosso não está livre da escassez. Em 2016, o município de Tangará da serra passou por uma crise de abastecimento de água que obrigou os moradores locais a buscarem fontes alternativas para suprirem suas necessidades.

A partir do relatório de monitoramento da qualidade de água realizado pela SEMA-MT no período de 2012 a 2014 compreendendo as três regiões hidrográficas existentes no estado (Amazônica, Paraguai e Tocantins-Araguaia) pode-se verificar as condições quanto à qualidade da água. Na região hidrográfica do Paraguai constataramse diversos trechos com classificação ruim em IQA, destacando-se o Rio vermelho, um importante curso d'água utilizado para abastecimento no município de Rondonópolis, que sofre um intenso processo de degradação causado por saneamento básico deficiente e uso e ocupação inadequada do solo. Porém as sub-bacias dessa região apresentam em sua maioria classificações regular e boa. De modo geral, a qualidade da água da Região Hidrográfica do Paraguai vem sofrendo degradação em alguns lugares, principalmente 


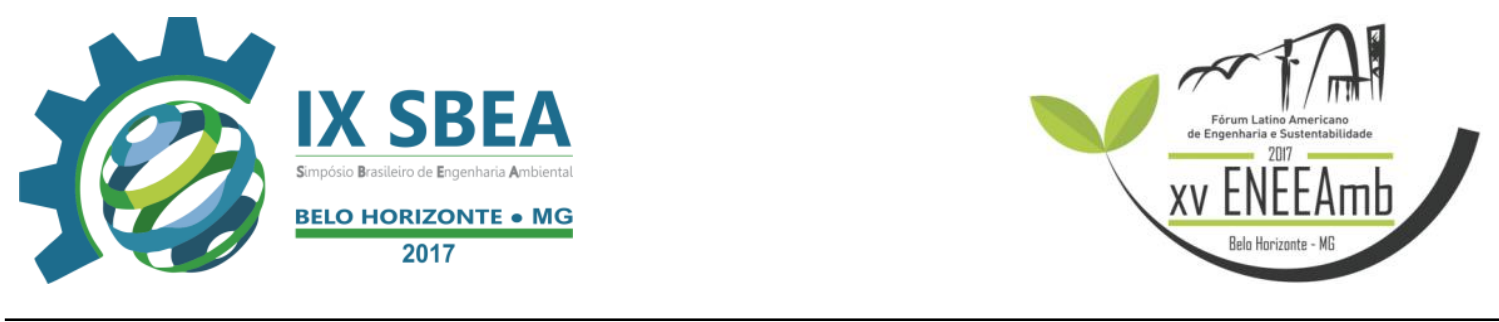

nos períodos chuvosos, especialmente na sub-bacia do Rio São Lourenço em virtude da intensificação das atividades antrópicas na região (SEMA, 2016).

A região hidrográfica das amazonas apresentou a classificação predominantemente boa, mas o relatório aponta que o desenvolvimento econômico que a região tem enfrentado poderá acarretar futuras complicações caso não haja um acompanhamento e manutenção da qualidade dos recursos hídricos nessa área. $\mathrm{Na}$ região hidrográfica Tocantins-Araguaia se percebe uma maior ocorrência de IQA com classificação Regular ao longo dos anos, com decréscimo de estações com classificação Boa (SEMA, 2016).

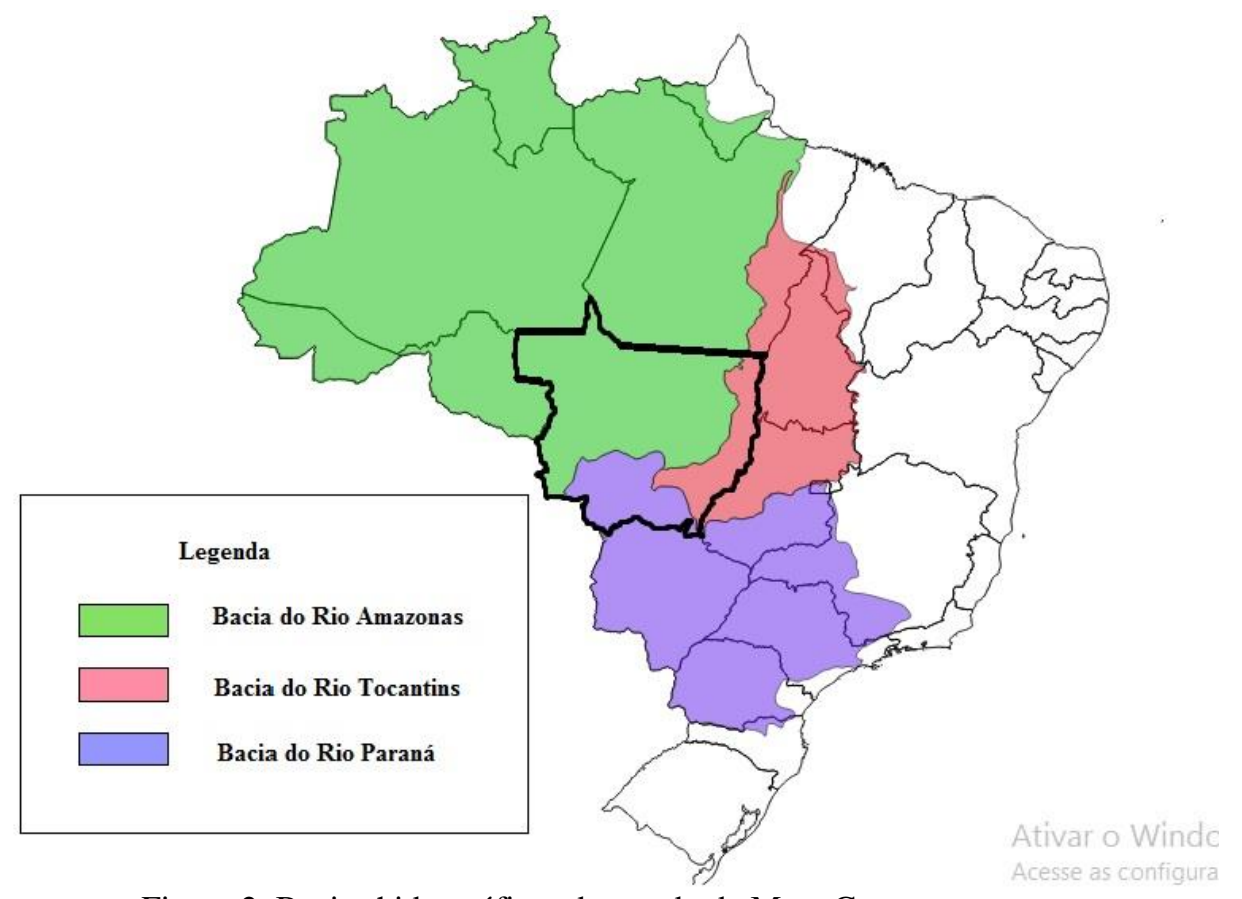

Figura 2. Bacias hidrográficas do estado de Mato Grosso.

\section{Projetos (ou ações/instrumentos) em desenvolvimento}

O Ministério Público do estado de Mato Grosso, em parceria com a Universidade Federal e Mato Grosso e o Instituto Ação Verde, executam o projeto "Água para o Futuro" que busca recuperar, preservar e identificar nascentes em Cuiabá, visando a garantia da segurança hídrica de Cuiabá e o abastecimento de água potável.

Outros projetos voltados para preservação e conservação dos recursos hídricos estão sendo realizados no estado, a Secretaria do Estado de Meio Ambienta (SEMA) além de ser encarregada de ações como monitoramento dos rios, efetivação do instrumento de outorga, incentivo ao Comitê de Bacias Hidrográficas (CBHs) também executa os projetos de "Pacto das Cabeceiras do Pantanal" e "Cultivando Água Boa".

Em junho de 2015 foi assinado o pacto entre o Governo do Estado e demais parceiros com o intuito de preservar as nascentes do Rio Paraguai, Sepotuba, Jauru e Cabaçal. Os municípios em que está sendo operado esse pacto são: Alto Paraguai, Araputanga, Arenápolis, Barra do Bugres, Cáceres, Curvelândia, Denise, Diamantino, Figueirópolis D’Oeste, Glória D’Oeste, Indiavaí, Jauru, Lambari D'Oeste, Mirassol 


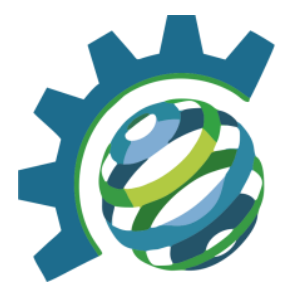

D'Oeste, Nortelândia, Nova Marilândia, Nova Olímpia, Porto Esperidião, Porto Estrela, Reserva do Cabaçal, Rio Branco, Santo Afonso, São José dos Quatro Marcos, Salto do Céu e Tangará da Serra. Algumas etapas desse projeto já estão concluídas e em andamento como identificação das nascentes que precisam ser recuperadas, diagnostico da bacia, instalação de biofossas entre outros.

A SEMA também está conduzindo o projeto "Cultivando Agua Boa", que foi firmado com a Hidrelétrica Itaipu Binacional e o Governo do Estado que tem como objetivo minimizar os impactos ambientais como aumento de temperatura, diminuição no volume de chuvas que por consequência levará a redução das vazões dos rios comprometendo o abastecimento de água e a adoção de modelos de produção sustentável.

\section{Desafios futuros}

Em virtude do que foi exposto anteriormente, mato grosso tem avançado no cenário de proteção aos recursos hídricos. Porém ainda existem muitos desafios para melhoria da atual situação. No que se refere à qualidade de água, o saneamento básico deficiente é o que mais tem contribuído para a degradação. O relatório da SEMA-MT aponta tal área como prioritária para buscar-se reverter o grau considerável de poluição de diversos rios da bacia do São Lourenço. O saneamento básico talvez seja a infraestrutura que mais pode contribuir com a quantidade e qualidade da água numa cidade, pois o acesso das casas à água tratada, coleta e tratamento dos esgotos faz com que a água dos esgotos seja devolvida aos rios em condições de ser recoletada e reutilizada (CBDES, 2015). Os planos de saneamento básico nos municípios que estão em fase de elaboração seriam nesse sentido uma ferramenta a ser considerada para mudanças futuras no quadro de recursos hídricos. NOARA e SCHULT (2010) destacam que o bom desempenho na gestão do saneamento nos municípios, depende também da articulação do seu plano de saneamento com o plano diretor de recursos hídricos e de uma articulação entre os atores sociais envolvidos, o que recentemente passou a ser chamado de uma boa governança no saneamento básico.

No tocante a proteção aos ecossistemas, os projetos desenvolvidos apresentados, se forem mantidos, serão indispensáveis para impulsionar um estágio de segurança hídrica desejável. Para evitar ou minimizar os impactos de eventos de escassez hídrica, a aposta certa, tende a ter foco em uma nova visão de gestão voltada ao planejamento estratégico e participação social efetiva. O plano estadual de recursos hídricos, lançado em 2009, surge como uma ferramenta para buscar-se uma gestão adequada. Outro ponto de interesse são as zonas de segurança hídrica. Os municípios têm por intermédio do zoneamento urbano, a criação de zonas de interesse hídrico que poderão auxiliar na identificação e classificação de nascentes, áreas úmidas, áreas de recarga de aquíferos, monitoramento de qualidade da água e, além disso, propor usos compatíveis para tais zonas.

Quanto a influência climática, é necessário à adoção de medidas contra eventos hidrológicos extremos considerando os efeitos das mudanças do clima. A projeção do agravamento das mudanças climáticas na América do Sul pelo $5^{\circ}$ Relatório do IPCC traz como uma das maiores implicações a questão da escassez da água (BOLSON, 2014). 


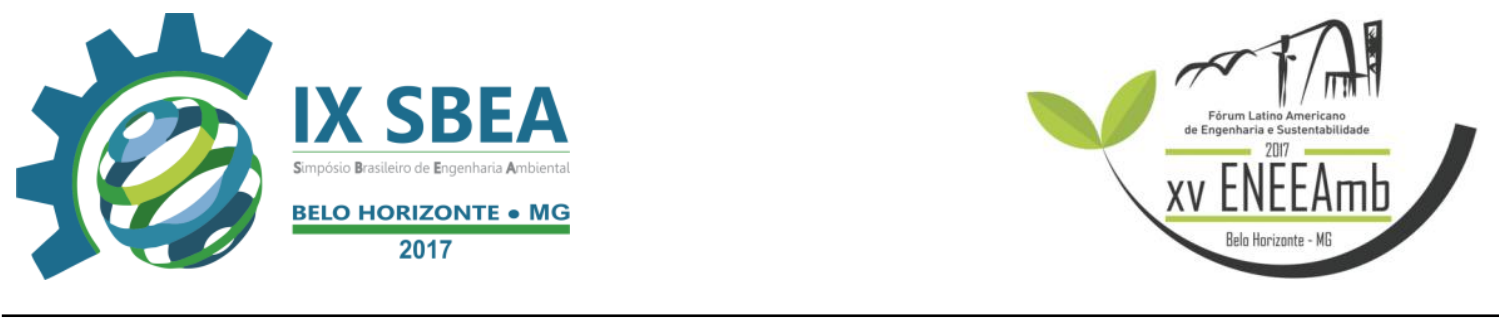

\section{CONCLUSÕES}

Diante do que foi exposto, existem diversas ameaças aos recursos hídricos no estado de Mato grosso e iniciativas já estão sendo realizadas para garantir o acesso em quantidade e qualidade para a população, que deve ser tratada como uma das grandes preocupações atuais. Porém investimentos ainda são necessários e adoção de medidas estruturantes. Os projetos em desenvolvimento têm conseguido avanços, com destaque para a atenção social que está sendo gerada com a divulgação destes e os desafios encontrados podem ser resolvidos desde que haja uma mudança na visão dos atores que compõe a gestão de recursos hídricos e aplicação de instrumentos já previstos nas legislações em nível federal e local.

\section{REFERÊNCIAS BIBLIOGRÁFICAS}

ANA (AGÊNCIA NACIONAL DE ÁGUAS) e MINISTÉRIO DA INTEGRAÇÃO NACIONAL. Termo de Referência PNSH. Brasília: ANA, 2012. Disponível em: $<\mathrm{http} / / /$ interaguas.ana.gov.br/Lists/Licitacoes_Docs/Attachments/32/TDR_PNSH_Preli minar.pdf $>$. Acesso em 18 abril 2017.

BOLSON, 2014. A vulnerabilidade hídrica no semiárido nordestino e na fronteira oeste do sul do brasil: agravamento com as mudanças climáticas e a necessidade de um plano nacional de segurança hídrica. Universidade Federal do Tocantins - UFT. BORGES, M. V. S \& ROSA, B. P. Gestão de Recursos Hídricos no Brasil. Revista de Direito, Economia e Desenvolvimento Sustentável, Minas Gerais, v.1, n. 2, p. 124-138, jul./dez. 2015.

CUIABÁ. Lei Complementar no 389 de 03 de Novembro de 2015. Disciplina o uso e ocupação do solo no município de Cuiabá. Disponível em: <http://www.cuiaba.mt.gov.br/storage/webdisco/2016/02/01/outros/f3295fc5flc3855e0 5e4d87a29b26578.pdf>. Acesso em 05 de abril de 2017.

MATO GROSSO, 2016. Governo do Estado de Mato Grosso. Secretaria de Estado do Meio Ambiente. Disponível em: http://www.mt.gov.br/-/3705372-mato-grosso-ereferencia-em-gestao-da-agua. Acesso em 10 abril 2017.

MATO GROSSO. Lei Estadual n ${ }^{\circ} 6.945$ de 05 de Novembro de 1997. Dispõe sobre a Política Estadual de Recursos Hídricos, institui o Sistema Estadual de Recursos Hídricos e dá outras providências. Disponível em:〈http://oads.org.br/leis/2913.pdf〉. Acesso em: 14 abril 2017.

NOARA \& SCHULT, 2010. Governança Ambiental local: os desafios na articulação e implementação da Política Nacional de Recursos Hídricos e de saneamento básico nos municípios da bacia do Rio Itajaí/SC. Encontro Nacional da ANPPAS. 2010. 


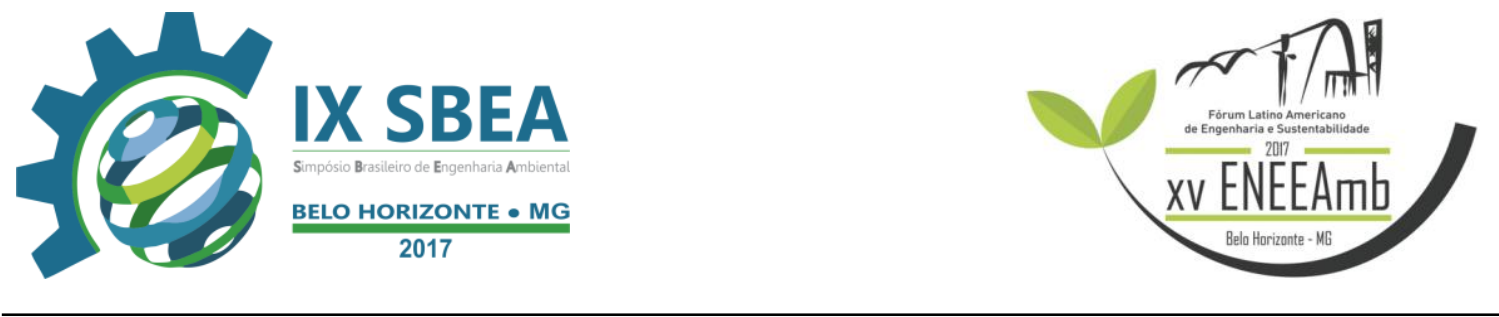

SANTOS, Bianca Borges Medeiros. Segurança hídrica da região metropolitana do Rio de Janeiro: contribuições para o debate. Ambiente \& Sociedade, São Paulo v. XIX, n. 1, p. 103-120, jan./mar. 2016.

SILVEIRA, G. L.; ROBAINA, A. D.; GIOTTO, E.; DEWES, R. Outorga para uso dos recursos hídricos: aspectos práticos e conceituais para o estabelecimento de um sistema informatizado. Revista Brasileira de Recursos Hídricos, v. 3, n. 3, p. 5-16, jul./set. 1998. Disponível em: <https://www.researchgate.net/profile/Adroaldo_Robaina/publication/266878102_Outo rga_para_uso_dos_recursos_Hidricos_Aspectos_praticos_e_conceituais_para_o_estabel ecimento_de_um_sistema_informatizado/links/54b11fcf0cf220c63ccf8e56/Outorgapara-uso-dos-recursos-Hidricos-Aspectos-praticos-e-conceituais-para-oestabelecimento-de-um-sistema-informatizado.pdf>. Acesso em: 02 abril 2017. 